OPEN ACCESS ISSN 25482254 (online) ISSN 20893833 (print)

Edited by: Enik Setiyawati Reviewed by: Vivi Permatasari

${ }^{*}$ Correspondence: Melania Priska pika87cutes@gmail.com

Received: 10 Agustus 2020 Accepted: 15 Agustus 2020 Published: 19 Agustus 2020

Citation:

Priska M, Pendy A, Peni N and Carvallo L (2020) Development of Learning Based on Problems in Chemistry Subjects to Improve Students' Critical Thinking Ability. PEDAGOGIA: Jurnal Pendidikan.

\section{Development of Learning Based on Problems in Chemistry Subjects to Improve Students' Critical Thinking Ability}

\section{Pengembangan Pembelajaran Berdasarkan Masalah Pada Mata Kuliah Kimia Untuk Meningkatkan Kemampuan Berpikir Kritis Mahasiswa}

\author{
Melania Priska*, Agnes Pendy, Natalia Peni, Ludovicus Carvallo \\ Fakultas Keguruan dan IImu Pendidikan, Universitas Flores, Indonesia
}

Solution material is one of the materials that require a student's level of understanding at the critical thinking level. Critical thinking skills train students to learn to find and solve problems using scientific methods based on real experiences encountered and experienced directly. To be able to find the concept of knowledge based on existing realities, an appropriate learning model is needed, namely a problem-based learning model. This study aims to determine students' critical thinking skills. The type and design of this research is development research with a nonequivalent control group design. The samples of this research were students of semester 2, Biology Education Study Program, University of Flores. This research was conducted from April-June 2020. Data were collected using the critical thinking ability test technique of students in the chemical solution subject, followed by processing and analyzing data using the prerequisite analysis test in the form of normality test, homogeneity test, and t-test. The data analysis shows the significant value of the normality and homogeneity test, namely $\alpha>0.05$, while for the t-test $\alpha<0.05$. From these results prove that problem-based learning can improve students' critical thinking skills in chemistry subject matter solution

Keywords: Development, Critical Thinking Ability, Problem-Solving, Solution

Materi larutan merupakan salah satu materi yang membutuhkan tingkat pemahaman mahasiswa pada taraf berpikir kritis. Kemampuan berpikir kritis melatih mahasiswa untuk belajar menemukan dan memecahkan masalah menggunakan metode ilmiah berdasarkan pengalaman nyata yang ditemui dan dialami secara langsung. Untuk dapat menemukan sendiri konsep pengetahuan berdasarkan realita yang ada dibutuhkan model pembelajaran yang tepat, yakni model pembelajaran berdasarkan masalah. Penelitian ini bertujuan untuk mengetahui kemampuan berpikir kritis mahasiswa. Adapun jenis dan desain penelitian ini adalah penelitian pengembangan dengan nonequivalent control group design. Sampel penelitian ini adalah mahasiswa semester 2, Program 
Studi Pendidikan Biologi Universitas Flores. Penelitian ini dilaksanakan dari bulan AprilJuni 2020. Data dikumpulkan dengan menggunakan teknik tes kemampuan berpikir kritis mahasiswa pada mata kuliah kimia materi larutan, dilanjutkan dengan pengolahan dan analisis data menggunakan uji prasyarat analisis berupa uji normalitas, uji homogenitas, dan uji-t. Data analisis menunjukkan nilai signifikansi uji normalitas dan homogenitas, yakni $\alpha>0,05$, sedangkan untuk uji-t $\alpha<0,05$. Dari hasil tersebut membuktikan bahwa pembelajaran berdasarkan masalah dapat meningkatkan kemampuan berpikir kritis mahasiswa pada mata kuliah kimia materi larutan.

Keywords: Development, Critical Thinking Ability, Problem-Solving, Solution

\section{PENDAHULUAN}

Peran ilmu kimia dalam kehidupan sejalan dengan perkembangan teknologi dan informasi saat ini. Pembelajaran kimia di tingkat perguruan tinggi harus mampu mentransferkan konsep kimia yang benar kepada mahasiswa, agar mudah dipahami dan diaplikasikan dalam kehidupan sehari-hari, serta mudah diingat Asmawati (2015). Proses pembelajaran di perguruan tinggi pada era revolusi indsutri 4.0 yang di tandai dengan berintegrasinya beberapa teknologi sekaligus seperti bilogi, fisika, dan digital, sehingga menuntut mahasiswa untuk memiliki kemampuan berpikir kritis agar konsep kimia yang ditransferkan dapat diuji kebenarannya Hidayanti et al. (2016). Berpikir kritis merupakan suatu proses penemuan secara sistematis menggunakan fakta yang ada dan dapat diterima oleh akal sehat Adean and Ratu (2019). Pada proses pembelajaran berpikir kritis, mahasiswa dilatih untuk belajar menemukan dan memecahkan masalah menggunakan metode ilmiah berdasarkan pengalaman, pengetahuan, ide-ide, konsep, serta mendengarkan pendapat teman sebaya sebagai pertimbangan dalam menarik kesimpulan terhadap gejala-gejala yang menyimpang dan kebenaran ilmiah Damayanti et al. (2012). Ciri mahasiswa yang berpikir kritis, yakni harus mampu mengklasifikasi, mengasumsi, memprediksi, menginterpretasikan, mengukur, merancang, mengamati, meminimalkan kesalahan, mengevaluasi dan menganalisis data hasil percobaan Dwijananti and Yulianti (2010).

Dalam mata kuliah kimia khususnya pada materi larutan, kemampuan berpikir kritis sangat diperlukan. Materi larutan adalah salah satu materi yang membutuhkan tingkat pemahaman mahasiswa pada taraf berpikir tingkat tinggi Azzahra (2019). Berdasarkan data hasil belajar selama 2 tahun terakhir mahasiswa program studi pendidikan biologi semester 2 Universitas Flores menunjukkan bahwa pemahaman mahasiswa terhadap materi larutan masih sangat rendah. Hasil tersebut dibuktikan dengan data yang disajikan pada Tabel 1

[Table 1 about here.]

Dari data pada Tabel 1 , maka dibutuhkan model pembelajaran dimana mahasiswa dapat menemukan sendiri konsep pengetahuan berdasarkan dengan realita yang ada, yakni model pembelajaran berdasarkan masalah (PBM). Model pembelajaran berdasarkan masalah melibatkan mahasiswa secara langsung dalam proses menemukan fakta dan informasi materi yang diajarkan untuk meningkatkan kemampuan berpikir kritis mahasiswa Ariyanti et al. (2015). Belajar berdasarkan masalah adalah interaksi antara stimulus dan respon, dimana terjadi hubungan belajar dua arah dengan lingkungan. Lingkungan memberikan masukan berupa masalah sebagai sumber belajar, sehingga sistem saraf pada otak mampu menafsirkan bantuan secara efektif agar masalah dapat diselidiki, dinilai, dianalisis, serta dicari pemecahannya melalui percobaan Rahmawati et al. (2013). Konsep pemecahan masalah pada model PBM dilakukan dengan langkah-langkah, yakni mengamati, mengajukan hipotesis, mengajukan pertanyaan, menggolongkan, menafsirkan data, mengkomunikasikan hasil temuan, menggali dan memilih informasi aktual untuk menguji gagasan Maryati (2018). Berkaitan dengan hal tersebut, maka perlu dilakukan implementasi model pembelajaran berdasarkan masalah (PBM) yang dapat meningkatkan kemampuan berpikir kritis mahasiswa. 


\section{METODE}

Penelitian ini dikategorikan sebagai penelitian eksperimen yaitu suatu penelitian yang tidak dilakukan randominasi untuk mengelompokkan subjek ke dalam kelompok eksperimen dan kelompok kontrol melainkan menggunakan kelompok subjek yang sudah ada sebelumnya. Penelitian ini dilaksanakan dari bulan April - Juni 2020, bertempat di Program Studi Pendidikan Biologi Fakultas Keguruan dan Ilmu Pendidikan Universitas Flores. Penelitian ini dilaksanakan pada masa pandemi covid 19,sehingga proses pembelajaran menggunakan google classrom. Dalam penelitian ini, yang menjadi populasi adalah seluruh mahasiswa Program Studi Pendidikan Biologi Semester II. Pengambilan sampel dilakukan secara acak. Yang menjadi sampel adalah mahasiswa program studi pendidikan biologi semester II sebanyak 20 orang.

Desain penelitian ini digunakan adalah nonequivalent control group design. Adapun desain penelitian tersebut dapat dilihat pada Tabel 2

[Table 2 about here.]

Keterangan:

$\mathrm{O}_{1}=$ Pre-test (tes awal yang diberikan kepada kelas eksperimen dan kelas kontrol)

$\mathrm{O}_{2}=$ Post-test (tes akhir yang diberikan kepada kelas eksperimen dan kelas kontrol)

$\mathrm{X}_{E}=$ Perlakuan terhadap kelas eksperimen menggunakan model pembelajaran berdasarkan masalah

$\mathrm{X}_{K}=$ Perlakuan terhadap kelas kontrol menggunakan model pembelajaran berdasarkan masalah

Adapun instrumen yang digunakan untuk mengumpulkan data dalam penelitian ini adalah tes berpikir kritis mata kuliah kimia, materi larutan. Indikator kemampuan berpikir kritis penelitian ini adalah mengemukkan hipotesis, meranang eksperimen, menaik kesimpulan sesuai dengan fakta danmenaik kesimpulan dari hasil penyelidikan serta mempresetasikan hasil percobaan di depan kelas seara lisan dan tulisan. Instrumen tes ini digunakan untuk mendapatkan data tentang kemampuan berpikir kritis mahasiswa sebelum dan sesudah implementasi model pembelajaran berdasarkan masalah. Bentuk tes yang diberikan berupa essay test, baik pada pretest dengan jumlah soal 5 nomor maupun posttest dengan jumlah soal sesuai dengan tujuan pembelajaran yang telah dibuat. Pretest diberikan pada saat sebelum pembelajaran dimulai baik pada kelas eksperimen maupun pada kelas kontrol, sedangkan posttest digunakan untuk mengukur kemampuan berpikir kritis mahasiswa setelah pembelajaran pada kelas eksperimen dan pada kelas kontrol.

Untuk mendapatkan data yang valid maka diperlukan instrumen yang valid dan reliabel sehingga instrumen penelitian tes kemampuan berpikir kritis dianalisis dengan menggunakan rumus korelasi pearson product moment, sedangkan untuk mengetahui tingkat keterhandalan instrumen agar dapat dipercaya, maka instrumen tersebut diuji dengan menggunakan rumus KR-21 Yusup (2018a). Teknik analisis data untuk kemampuan berpikir kritis dilakukan secara statistik. Hal ini dilakukan untuk mengetahui bahwa penggunaan model pembelajaran berdasarkan masalah yang diberikan pada kelas eksperimen lebih dapat meningkatkan kemampuan berpikir kritis mahasiswa daripada sebelum penggunaan model pembelajaran berdasarkan masalah pada kelas kontrol sehingga penganalisisan data pada penelitian ini dilakukan secara statistik dengan menggunakan uji-t. Akan tetapi sebelumnya digunakan uji normalitas dan uji homogenitas sebagai syarat agar dapat dilakukan analisis data Farisi et al. (2017).

\section{HASIL DAN PEMBAHASAN}

\section{Hasil Uji Validitas}

Untuk mengetahui keefektifan soal pretest maupun posttest sebelum digunakan, dilakukan terlebih dahulu uji validitas. Validitas menunjukkan ketepatan dan kesahihan instrumen butir soal yang digunakan Yusup (2018a). Uji validitas instrumen pada penelitian ini menggunakana SPSS versi 21.0. Data hasil validitas instrumen butir soal dapat dilihat pada Tabel 3 . 
[Table 3 about here.]

Uji validitas intrumen dari 5 butir soal essay menggunakan korelasi produk momen (r) diperoleh nilai $\mathrm{r}_{\text {hitung }}$ untuk setiap butir soal berada pada kategori valid. Nilai $\mathrm{r}_{\text {hitung }}$ dari hasil uji validitas untuk setiap butir soal memiliki $\mathrm{r}_{h i t u n g}>\mathrm{r}_{\text {tabel }}$, yakni 0,444 Muaja et al. (2013).

\section{Hasil Uji Reliabel}

Untuk mendukung hasil uji validitas, perlu dilakukan uji reliabilitas pada instrumen butir soal yang akan digunakan. Uji reliabel menunjukkan konsistensi suatu instrumen, yang mana suatu instrumen dapat dipercaya dan dapat diandalkan dalam pengujian yang sama dan tempat yang berbeda MuhammadKhumaedi (2012). Pengukuran reliabilitas instrumen mengacu pada interval koefisien reliabel yang dapat dilihat pada tabel 4 .

[Table 4 about here.]

Data hasil uji reliabilitas instrumen butir soal disajikan pada tabel 5.

[Table 5 about here.]

Dari 5 butir soal essay seperti yang terdapat pada tabel 5, menunjukkan bahwa total keseluruhan 5 butir soal yang digunakan berada pada kategori reliabel atau dapat dipercaya dan dapat diandalkan. Hal tersebut ditunjukkan dari nilai Cronbach's Alpha yang memiliki tingkat hubungan tinggi, karena berada pada interval koefisien 0,600-0,799 Sukma et al. (2017).

\section{Hasil Uji Normalitas}

Sebaran data kemampuan berpikir kritis mahasiswa semester 2 program studi pendidikan biologi pada mata kuliah kimia materi larutan dapat ditentukan melalui uji normalitas. Dari hasil uji normalitas dapat diketahui apakah sebaran data berdistibusi normal atau tidak. Uji nomalitas dianalisis dengan menggunakan uji Kolmogorov-Smirnov. Data hasil uji nomalitas disajikan padaTabel 6 .

[Table 6 about here.]

BerdasarkanTabel 6 , dapat dilihat bahwa nilai normalitas kemampuan berpikir kritis mahasiswa pada mata kuliah kimia materi larutan untuk kelas kontrol dan kelas eksperimen memiliki sebaran data berdistribusi normal. Hal tersebut ditunjukkan dari hasil analisis uji normalitas soal pretest maupun posttest yang memiliki nilai $\alpha>0,05$. Dari hasil tersebut menyatakan bahwa penggunaan pembelajaran berdasarkan masalah (PBM) dapat meningkatkan kemampuan berpikir kritis mahasiswa.

Dalam teori John Dewey, pembelajaran pada orang dewasa harus diajarkan proses berpikir yang benar karena membuka cakrawala berpikir mahasiswa untuk dapat merumuskan atau memecahkan masalah, membuat keputusan, atau memenuhi keinginan untuk memahami Rachmadtullah (2015). Jika ketiga hal tersebut dipenuhi, maka mahasiswa memiliki kemampuan berpikir kritis. Berpikir kritis merupakan suatu proses yang tersistematis dan terorganisir untuk menemukan kebenaran dari suatu infomasi, dimana mahasiswa dapat melakukan penganalisisan suatu masalah demi mencapai pemahaman yang mendalam (Fakhriyah, 2014).

\section{Hasil Uji Homogenitas}

Uji homogenitas digunakan untuk menganalisis perbedaan variansi antara 2 (dua) perlakuan, yakni kelas kontrol dan eksperimen. Data hasil analisis disajikan padaTabel 7 .

[Table 7 about here.] 
Berdasarkan hasil uji homogenitas varian pada Tabel 7 dapat diketahui nilai signifikansi $\alpha>0,05$, yakni 0,717 . Data ini menunjukkan bahwa tidak ada pebedaan varian antara 2 (dua) perlakuan Handika and Wangid (2013). Dengan tidak adanya perbedaan varian antara 2 perlakuan, mau membuktikan bahwa kemampuan mahasiswa pada kelas kontrol dan kelas eksperimen adalah sama. Keberhasilan pembelajaran berdasarkan masalah disebabkan karena proses pembelajarannya memotivasi mahasiswa untuk menyelesaikan permasalahan selanjutnya, mengkomunikasikan hasil pemikiran melalui diskusi kelompok, dan mempresentasikan di depan kelas hasil identifikasi masalah yang ditemukan Sari et al. (2014). Hal tersebut mendorong mahasiswa untuk selalu mengembangkan hasil karya dan terus berpartisipasi aktif dalam proses pembelajaran.

\section{Hasil Uji-t}

Adanya pengaruh dari masing-masing variabel bebas terhadap variabel terikatnya pada kelas eksperimen dan kelas kontrol dapat diketahui dengan menganalisis secara parsial data, atau yang dikenal dengan uji t. Uji $\mathrm{t}$ merupakan uji hipotesis perbedaan dua rata-rata yang dilakukan setelah uji prasyarat analisis yang menghasilkan data pengetahuan awal pembelajaran berdasarkan masalah yang berdistribusi normal dan homogen. Pada tabel 8 disajikan hasil uji hipotesis mengenai pengaruh pembelajaran berbasis masalah terhadap kemampuan berpikir kritis mahasiswa menggunakan uji paired sample test.

[Table 8 about here.]

Hasil uji t menggunakan uji paired sample test pada Tabel 8 didapat hasil signifikansi $\alpha$ pada kelas kontrol dan kelas eksperimen $<0,05$, yakni 0,000 . Kedua hasil tersebut menunjukkan bahwa terdapat pengaruh pembelajaran berdasarkan masalah terhadap peningkatan kemampuan berpikir kritis mahasiswa pada mata kuliah kimia materi larutan. Penerapan pembelajaran berdasarkan masalah memacu kemampuan berpikir kritis mahasiswa untuk dapat berkembang lebih baik daripada sebelum menggunakan pembelajaran berdasarkan masalah melalui proses pemecahan masalah yang rumit dalam kelompok diskusi kecil, sehingga kemampuan mengidentifikasi, evaluasi, penalaran logis, interpretasi mahasiswa menjadi lebih baik Rosa and Pujiati (2017) .

Kemampuan berpikir kritis mahasiswa cenderung lebih rendah sebelum diterapkan model pembelajaran berdasarkan masalah. Hal tersebut disebabkan mahasiswa dibuat pasif dan hanya mendengarkan dari satu arah saja, yakni dari dosen tanpa pengaplikasian konsep dalam kehidupan nyata Maryam et al. (2020) . Pengaplikasian konsep dalam kehidupan nyata dapat melatih mahasiswa untuk menemukan fakta, konsep, dan prinsip melalui masalah-masalah yang bersifat open-ended ataupun fenomena nyata yang ditemui dan dialami secara langsung Marhamah et al. (2020).

\section{KESIMPULAN}

Pembelajaran berdasarkan masalah dapat meningkatkan kemampuan berpikir kritis mahasiswa Program Studi Pendidikan Biologi Universitas Flores pada mata kuliah kimia materi larutan.

\section{UCAPAN TERIMA KASIH}

Peneliti mengucapkan terima kasih kepada Direktorat Jenderal Pendidikan Tinggi yang telah memberikan bantuan dana Penelitian Dosen Pemula (PDP) tahun anggaran 2020, sehingga penelitian ini dapat terlaksana dengan baik. 


\section{REFERENCES}

Adean, M. and Ratu, F. I. R. (2019). Perbandingan Pembelajaran Problem Based Learning dan Guided Inquiry Terhadap Kemampuan Berpikir Kritis pada Materi Laju Reaksi. Journal of Education Science (JES) 5, 57-69.

Ariyanti, N. D., Haryono, and Masykuri, M. (2015). Peningkatan Kemampuan Berpikir Kritis dan Prestasi Belajar Siswa pada Materi Stoikiometri dengan Menggunakan Model Pembelajaran Problem Solving berbantuan Modu di Kelas X MIA 2 SMA Negeri 1 Banyudono Tahun Pelajaran. Jurnal Pendidikan Kimia (JPK) 6, 62-68.

Asmawati, E. Y. (2015). LEMBAR KERJA SISWA (LKS) MENGGUNAKAN MODEL GUIDED INQUIRY UNTUK MENINGKATKAN KETERAMPILAN BERPIKIR KRITIS DAN PENGUASAAN KONSEP SISWA. Jurnal Pendidikan Fisika 3, 1-16. doi 10.24127/jpf.v3i1.13.

Azzahra, S. F. (2019). Peningkatan Kemampuan Berfikir Kritis Siswa Melalui Pembelajaran Eksperimen pada Mater Larutan Elektrolit dan Non Elektrolit. Jurnal EduMatSains 4, 77-88. doi: https://doi.org/10.33541/edumatsains.v4i1. 1046.

Damayanti, D. S., Ngazizah, N., and K, E. S. (2012). Pengembangan Lembar Kerja Siswa (LKS) dengan Pendekatan Inkuiri Terbimbing untuk Mengoptimalkan Kemampuan Berpikir Kritis Peserta Didik pada Materi Listrik Dinamis SMA Negeri 3 Purwerejo Kelas X Tahun Pelajaran. Radiasi 3, 58-62.

Dwijananti, P. and Yulianti, D. (2010). Pengembangan Kemampuan Berpikir Kritis Mahasiswa melalui Pembelajaran Problem Based Instruction pada Mata Kuliah Fisika Lingkungan. Jurnal Pendidikan Fisika Indonesia 6, 108 114.

Fakhriyah, F. (2014). Penerapan Problem Based Learning dalam Upaya Mengembangkan Kemampuan Berpikir Kritis Mahasiswa. Jurnal Pendidikan IPA Indonesia 3, 95-101.

Farisi, A., Hamid, A., and Melvina (2017). Pengaruh Mode Pembelajaran Problem Based Learning terhadap Kemampuan Berpikir Kritis dalam Meningkatkan Hasil Belajar Siswa pada Konsep Suhu dan Kalor. Jurnal Ilmiah Mahasiswa 2, 283-287.

Handika, I. and Wangid, M. N. (2013). PENGARUH PEMBELAJARAN BERBASIS MASALAH TERHADAP PEN GUASAAN KONSEP DAN KETERAMPILAN PROSES SAINS SISWA KELAS V. Jurnal Prima Edukasia 1, 85-85. doi: 10.21831/jpe.v1i1.2320.

Haryanti, Y. D. (2017). Model Problem Based Learning Mem bangun Kemampuan Berpikir Kritis Siswa Sekolah Dasar. Jurnal Cakrawala Pendas 3, 57-63.

Hidayanti, D., As'ari, A. R., and C, T. D. (2016). Analisis Kemampuan Berpikir Kritis Siswa Kelas IX pada Mater Kesebangunan. In Prosiding Konferensi Nasional Penelitian Matematika dan Pembelajarannya (KNPMP I), ed and others (Surakarta: Publikasi Ilmiah), 276-285.

Marhamah, I., Yahdi, and Hajaroh, S. (2020). Pengaruh Mode Pembelajaran Problem Based Learning terhadap Keterampilan Berpikir Kritis. SPIN JURNAL KIMIA DAN PENDIDIKAN 2, 68-82. doi: https://doi.org/10.20414/spin. v2i1.2012.

Maryam, M., Kusmiyati, K., Merta, I. W., and Artayasa, I. P. (2020). Pengaruh Model Pembelajaran Inkuiri Terhadap Keterampilan Berpikir Kritis Siswa. Jurnal Pijar Mipa 15, 206-206. doi: 10.29303/jpm.v15i3.1355.

Maryati, I. (2018). Penerapan Model Pembelajaran Berbasis Masalah pada Materi Pola Bilangan di Kelas VII Seko- lah Menengah Pertama. Jurnal Mosharafa 7, 63-74. doi: https://doi.org/10.31980/mosharafa.v7i1.342.

Muaja, J. R. T., Setiawan, A., and Mahatma, T. (2013). Uji Validitas dan Uji Reliabilitas menggunakan Metode Bootstrap pada Data Kuisioner Tipe Yes/No Question. Prosiding Seminar Nasional Sains dan Pendidikan Sains VIII. Fakultas Sains dan Matematika 4, 513-519.

MuhammadKhumaedi (2012). Reliabilitas Instrumen Penelitian Pendidikan. Jurnal Pendidikan Teknik Mesin 12, 2530.

Rachmadtullah, R. (2015). Kemampuan Berpikir Kritis dan Konsep Diri dengan Hasil Belajar Pendidikan Kewarganegaraan Siswa Kelas V Sekolah Dasar. Jurnal Pendidikan Dasar 6, 287-298. doi: https://doi.org/10.21009/JPD.062. 10.

Rahmawati, A. D., Riyadi, and Subanti, S. (2013). ANALISIS PROSES PEMBELAJARAN BERBASIS MASALAH (PROBLEM BASED LEARNING) MATEMATIKA DENGAN PENDEKATAN ILMIAH (SCIENTIFIC APPROACH ) DI SMA NEGERI 1 JOGOROGO KELAS X KABUPATEN NGAWI. Jurnal Pembelajaran Matematika 4, 64-75.

Rosa, N. M. and Pujiati, A. (2017). Pengaruh Model Pembelajaran Berbasis Masalah Terhadap Kemampuan Berpikir Kritis dan Kemampuan Berpikir Kreatif. Formatif: Jurnal Ilmiah Pendidikan MIPA 6, 175-183. doi: 10.30998/ formatif.v6i3.990

Sari, D. T., Kristiani, and Wardani, D. K. (2014). Penerapan Model PBL untuk Meningkatkan Kemampuan Berpikir Kritis dan Hasil Belajar Siswa pada Materi Ekonomi di SMA Negeri 3 Surakarta Tahun Pelajaran. vol. 1 of 1 , In Prosiding Seminar Nasional Pendidikan Ekonomi \& Bisnis, Fakultas Keguruan dan Ilmu Pendidikan (Surakarta: Prosiding Seminar Nasional Pendidikan Ekonomi \& Bisnis), 978-602. doi: https://doi.org/10.20961/bise.vli1.19918.

Sukma, F. B., Handayanto, S. K., and Kusairi, S. (2017). Pengembangan Instrumen Penguasaan Konsep dalam Pembelajaran Group Investigation. Jurnal Pendidikan: Teori, Penelitian, dan Pengembangan 2, 826-832.

Triana, D. and Widyarto, W. O. (2013). Relevansi Kualifikasi Kontraktor Bidang Teknik Sipil terhadap Kualitas Pekerjaan Proyek Konstruksi di Provinsi Banten. Jurnal Fondasi 1, 182-190.

Yusup, F. (2018a). Uji Validitas dan Reliabilitas Instrumen Penelitian Kuantitatif. Jurnal Tarbiyah : Jurnal Ilmiah Kependidikan 7, 17-23. doi: 10.18592/tarbiyah.v7i1.2100.

Yusup, F. (2018b). Uji Validitas dan Reliabilitas Instrumen Penelitian Kuantitatif. Jurnal Tarbiyah : Jurnal Ilmiah Kependidikan 7, 17-23. doi: 10.18592/tarbiyah.v7i1.2100.

Conflict of Interest Statement: The authors declare that the research was conducted in the absence of any commercial or financial relationships that could be construed as a potential conflict of interest.

Copyright (c) 2020 Priska, Pendy, Peni and Carvallo. This is an open-access article distributed under the terms of the Creative Commons Attribution License (CC BY). The use, distribution or reproduction in other forums is permitted, provided the original author(s) and the copyright owner(s) are credited and that the original publication in this journal is cited, in accordance with accepted academic practice. No use, distribution or reproduction is permitted which does not comply with these terms. 


\section{LIST OF TABLES}

Persentase Hasil Belajar Kimia 2 Tahun Terakhir . . . . . . . . . . . . 170

Desain Penelitian . . . . . . . . . . . . . . . . 171

Hasil Validitas Instrumen Butir Soal . . . . . . . . . . . . . . 172

IntervalKoefisien Reliabel (Triana \& Widyarto, 2013) . . . . . . . . . . . 173

Hasil Reliabel Instrumen Butir Soal . . . . . . . . . . . . . . . . . . . . . . . . . . . . . . . . . . . .

HasilUji Normalitas . . . . . . . . . . . . . . . . . . . . . . . . . . . . . . . . . . . . . . . . . . . . . . .

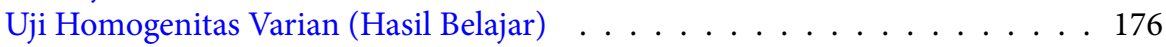

Uji Paired Sample Test . . . . . . . . . . . . . . . . . . . . . . 177 
TABLE 1 | Persentase Hasil Belajar Kimia 2 Tahun Terakhir

\begin{tabular}{lll} 
Nilai & $2018 / 2019$ & $2019 / 2020$ \\
A & - & $10 \%$ \\
& $49,67 \%$ & $52 \%$ \\
C & $47,67 \%$ & $34 \%$ \\
D & $2,66 \%$ & $4 \%$ \\
E & - & - \\
\hline
\end{tabular}


Priska et[aevelopment of Learning Based on Problems in Chemistry Subjects to Improve Students' Critical Thinking Ability

TABLE 2 | Desain Penelitian

\begin{tabular}{llll} 
Kelompok & Pretest & Treatment & Posttest \\
Eksperimen & O1 & XE & O2 \\
Kontrol & O1 & XK & O2 \\
\hline
\end{tabular}

Kontrol

$\mathrm{XK}$

$\mathrm{O} 2$ 
Priska et[aevelopment of Learning Based on Problems in Chemistry Subjects to Improve Students' Critical Thinking Ability

TABLE 3 | Hasil Validitas Instrumen Butir Soal

\begin{tabular}{lll}
\hline Nomor Soal & Nilai rhitung & Keterangan \\
\hline S1 & 0,765 & Valid \\
S2 & 0,747 & Valid \\
S3 & 0,730 & Valid \\
S4 & 0,674 & Valid \\
S5 & 0,681 & Valid \\
\hline
\end{tabular}


TABLE 4 | IntervalKoefisien Reliabel (Triana \& Widyarto, 2013)

\begin{tabular}{ll}
\hline Interval Koefisien & Tingkat Hubungan \\
\hline $0,800-1,000$ & Sangat Tinggi \\
$0,600-0,799$ & Tinggi \\
$0,400-0,599$ & Cukup \\
$0,200-0,399$ & Rendah \\
$0,000-0,199$ & Sangat Rendah
\end{tabular}


TABLE 5 | Hasil Reliabel Instrumen Butir Soal

\begin{tabular}{lll}
\hline Nomor Soal & Nilai Cronbach's Alpha & Keterangan \\
\hline S1 & 0,701 & Reliabel \\
S2 & 0,705 & Reliabel \\
S3 & 0,710 & Reliabel \\
S4 & 0,736 & Reliabel \\
S5 & 0,753 & Reliabel \\
\hline
\end{tabular}


TABLE 6 | HasilUji Normalitas

\begin{tabular}{clll}
\hline Mahasiswa & $\begin{array}{l}\text { Kolmogorov- } \\
\text { Smirnova }\end{array}$ & \\
& $\begin{array}{l}\text { Statistic } \\
\text { Pretest Kontrol }\end{array}$ & df & Sig. \\
Hasil Posttest Kontrol &, 124 & 20 &, $200^{\star}$ \\
Belajapretest Ekperimen &, 129 & 20 &, $200^{\star}$ \\
Posttest Eksperimen &, 146 & 20 &, $200^{\star}$ \\
\hline
\end{tabular}


TABLE 7 | Uji Homogenitas Varian (Hasil Belajar)

$\begin{array}{llll}\text { Levene Statistic } & \mathrm{df1} & \mathrm{df2} & \text { Sig. } \\ , 452 & 3 & 76 & , 717\end{array}$


Priska et[aevelopment of Learning Based on Problems in Chemistry Subjects to Improve Students' Critical Thinking Ability

TABLE 8 | Uji Paired Sample Test

\begin{tabular}{|c|c|c|c|c|c|c|c|c|}
\hline & \multicolumn{5}{|c|}{ Paired Differences } & \multirow[t]{3}{*}{$\mathrm{t}$} & \multirow[t]{3}{*}{$d f$} & \multirow[t]{3}{*}{ Sig. (2-tailed) } \\
\hline & \multirow[t]{2}{*}{ Mean } & \multirow[t]{2}{*}{$\begin{array}{l}\text { Std. } \\
\text { Deviation }\end{array}$} & \multirow[t]{2}{*}{$\begin{array}{l}\text { Std. } \\
\text { Error } \\
\text { Mean }\end{array}$} & \multicolumn{2}{|c|}{$\begin{array}{l}95 \% \text { Confidence } \\
\text { Interval of the Dif- } \\
\text { ference }\end{array}$} & & & \\
\hline & & & & Lower & Upper & & & \\
\hline $\begin{array}{l}\text { Pretest- } \\
\text { Posttest Kontrol }\end{array}$ & $-4,550$ & 1,761 & ,394 & $-5,374$ & $-3,726$ & $-11,552$ & 19 &, 000 \\
\hline $\begin{array}{l}\text { Pretest- } \\
\text { Posttest Eksperimen }\end{array}$ & $-3,800$ & 2,262 &, 506 & $-4,859$ & $-2,741$ & $-7,513$ & 19 &, 000 \\
\hline
\end{tabular}

